\title{
Tribological Properties of Carbon/PEEK Composites
}

\author{
Sung-Won Yoon ${ }^{1}$, Yun-Hae Kim ${ }^{2}$, Jin-Woo Lee ${ }^{2}$, Han-Bin Kim ${ }^{2}$ \\ and Ri-ichi Murakami ${ }^{1}$ \\ ${ }^{I}$ Dept. of Mechanical Engineering, The University of Tokushima, Tokushima, Japan \\ ${ }^{2}$ Dept. of Marine Equipment Engineering, Korea Maritime and Ocean University, Dongsam-dong, Youngdo-gu, Busan, Korea
}

(Manuscript Received June 25 2013; Revised July 28, 2013; Accepted August 19, 2013)

\begin{abstract}
In this study, the effect of Carbon/PEEK composites on the tribological properties has been investigated. Also, its validity has been tested in the capacity of alternative materials of the Ti-based materials used for artificial hip joint. Moreover, this work evaluated the mechanical properties according to the fiber ply orientation, along with the fractured surfaces of the carbon/PEEK composites. The composites with a unidirectional orientation had higher tribological properties than those with a multidirectional orientation. This was caused by the debonding between the carbon fiber and the PEEK, which was proportional to the contact area between the sliding surface and the carbon fiber. The friction test results showed that there were no significant differences in relation to the fiber ply orientation. However, the friction properties of the carbon/PEEK composites were higher than those of the carbon/epoxy composites. In addition, the results showed that a composite that slid in a direction normal to the prepreg lay-up direction had a smaller friction coefficient than one that slid in a direction parallel to the prepreg lay-up direction.
\end{abstract}

Keywords: Carbon fiber, Composites, Epoxy, Mechanical properties, PEEK, Tribological

\section{Introduction}

The average span of human's life has increased by the development of the medical technology. Therefore, health problems in the older generation have emerged as social problem. In particular, activities become more difficult because of deformations in the skeletal system and the development of disease, which lower the quality of life. For this reason, the artificial hip joint was developed to regain lost functions. [1 3]

An artificial hip joint consists of a cup, head, and stem. Most of the stems are manufactured from Ti, Co-chrome, or stainless steel alloys. However, metal materials deliver small scale stress to an arbitrary area of the bone as a result of the difference in rigidity.

${ }^{*}$ Corresponding author. Tel.: +82-51-410-4355, Fax.: +82-51-410-4350, E-mail address: yunheak@hhu.ac.kr Copyright C KSOE 2013.
Metal materials also atrophy the femur, causing bone loss. In addition, a problem arises whereby the implant device loosens as a result of the stress shielding between the metal material and the bone, shortening the life of the joint. Therefore, a substitute composite material needs to be found to resolve this problem. [4 7]

Epoxy resin is the most widely used matrix material for composite materials because of its comparatively low cost. However, because it is harmful to the human body, the development of a substitute material is urgently required.

In addition, fiber-reinforced composites significantly differ in their mechanical properties according to the ply orientation of the fiber. Currently, in the case of carbon/epoxy composites, various studies are being conducted in relation to the ply orientation of the fiber. However, in the case of carbon/PEEK composites, 
there is a lack of objective data. Moreover, in the human body, an artificial hip joint is placed in a constant friction environment for a long period. Particularly, the neck part of the stem becomes weak due to the friction from the interaction of the head and cup. Moreover, artificial joint needs to be investigated in terms of the change in intensity according to the fiber ply orientation of the carbon/PEEK composites because of the stress it receives at various ply orientation. $[8,9]$

Therefore, in this study, carbon/PEEK composites and carbon/Epoxy composites were fabricated, and the different mechanical properties according to the friction were investigated through a friction test. Simultaneously, we considered the effect of friction in relation to the mechanical properties of the carbon/PEEK composites and carbon/epoxy composites according to the ply orientation angle and friction angle of the fiber. From these results, it were investigated that the carbon/PEEK composites were applicable to artificial hip joints.

\section{Materials and Experiment Method}

\subsection{Materials and Specimens}

Experimental materials were prepared to measure the tribological properties of carbon/PEEK composites and carbon/epoxy composites. The carbon fiber of PAN-based UD tape was used for the reinforcing material. In addition, a thermoplastic PEEK film in from the Victrex Company was used as a matrix material. Also,
KFR121/KFH141 epoxy resin from the Kukdo Company was selected to compare the mechanical properties with PEEK film. The properties of the fiber and resin used in the experiment are shown in Table 1.

Carbon/PEEK semi-prepreg was made. The PEEK film and epoxy resin were used as the matrix materials for manufacturing the prepreg. In the case of the PEEK prepreg, the prepreg sheet was made using PEEK film of the same size and was laminated on both surfaces of the carbon fiber in a hot press with a pressure of $10 \mathrm{MPa}$ at $400{ }^{\circ} \mathrm{C}$. Thereafter, the carbon fiber prepreg was laminated at various angles in order to confirm the change in the mechanical properties according to the ply orientation angle of the fiber. Subsequently, composite materials were fabricated by operating the hot press at $380^{\circ} \mathrm{C}$ using the hot press molding method with the prepreg.

In the case of the epoxy prepreg, the epoxy resin (KFR121) and hardening agent (KFH141) were impregnated by mixing at a 100:30 ratio according to the table of mixing ratios provided by the resin manufacturing company. The direct impregnation method used a beaker and roller for the resin impregnation. The resin impregnation ratio was $45 \%$. The resin impregnated fiber was dried for $3 \mathrm{~h}$ at $50^{\circ} \mathrm{C}$ inside a vacuum drying oven, and refrigeration was maintained by attaching a release film to both sides. An autoclave was operated using a vacuum bag molding method at $174^{\circ} \mathrm{C}$ for $1 \mathrm{~h}$, and the composites were made.

Table 1. Properties of Fiber and Resin for Tests

\begin{tabular}{l|l|l|l|c}
\hline \hline Fiber & $\begin{array}{l}\text { Density } \\
{\left[\mathrm{g} / \mathrm{cm}^{3}\right]}\end{array}$ & $\begin{array}{l}\text { Tensile strength } \\
{[\mathrm{MPa}]}\end{array}$ & $\begin{array}{l}\text { Young's Modulus } \\
{[\mathrm{GPa}]}\end{array}$ & $\begin{array}{l}\text { Poisson's ratio } \\
{[\mathrm{v}]}\end{array}$ \\
\hline Carbon Fiber (UD) & 1.7 & 4400 & 245 & 0.2 \\
\hline \hline Resin & $\begin{array}{l}\text { Density } \\
{\left[\mathrm{g} / \mathrm{cm}^{3}\right]}\end{array}$ & $\begin{array}{l}\text { Tensile strength } \\
{[\mathrm{MPa}]}\end{array}$ & $\begin{array}{c}\text { Elastic Modulus } \\
{[\mathrm{GPa}]}\end{array}$ & $\begin{array}{c}\text { Elongation } \\
\text { Break } \\
{[\%]}\end{array}$ \\
\hline Epoxy Resin & 1.1 & 70 & 3.0 & 60 \\
\hline PEEK Film & 1.3 & 130 & 2.5 & 150 \\
\hline
\end{tabular}




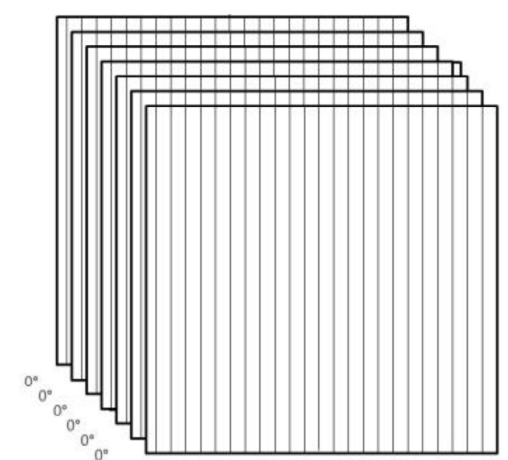

(a) Configuration I

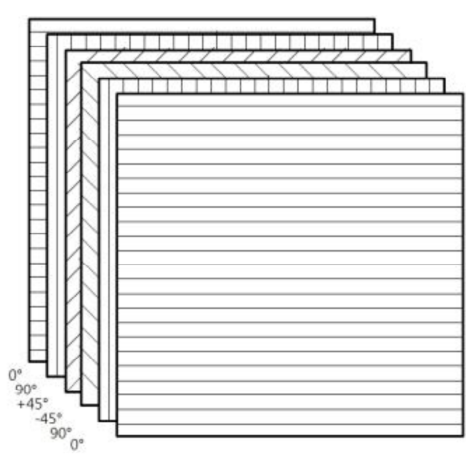

(b) Configuration II

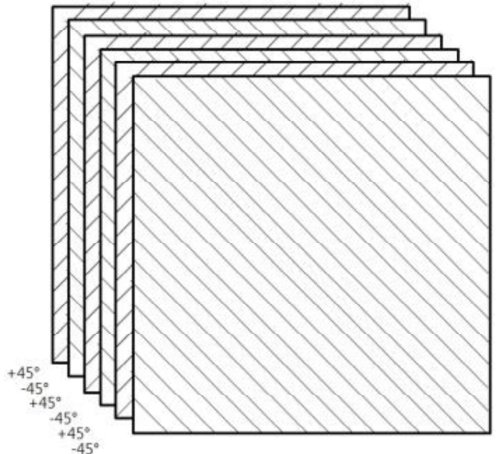

(c) Configuration III

Fig. 1. Ply Configurations for Carbon Fiber : (a) $\left[\left(0^{\circ}\right)_{6}\right]$, (b) $\left[\left( \pm 45^{\circ}\right)_{1}\left(0^{\circ} / 90^{\circ}\right)_{1}\left( \pm 45^{\circ}\right)_{1}\right]$, (c) $\left[\left( \pm 45^{\circ}\right)_{3}\right]$

\subsection{Experiment Method}

A test machine for the pin-on-disc test was used in order to observe the frictional properties of the carbon/PEEK and carbon/epoxy composites. Stainless steel was used as the relative friction surface and the normal load was fixed at $20 \mathrm{~N}$. The friction angles were separated into the parallel and normal directions in order to investigate the frictional property according to the fiber ply orientation and friction angle, and the friction coefficient was investigated. The friction velocity was $2.5 \mathrm{~m} / \mathrm{s}$. The humidity was maintained $37^{\circ} \mathrm{C}$ the experiment. At the same time, the damaged the specimen of the composites were observed using scanning electron microscope.

\section{Results and discussion}

\subsection{Tribological Properties}

The test was progressed for the friction coefficients according to the fiber ply orientation. The results of the friction coefficient are shown in Fig. 2. The carbon/PEEK and carbon/epoxy composites showed similar trends. As shown in the figure, the friction coefficient was larger in the direction parallel to the relative friction surface. In addition, no clear difference in the friction coefficient was found in relation to the carbon fiber ply orientation. However, in the case of the direction parallel to the relative friction surface, the sizes of the friction coefficient had the order of configurations I, III, and II. In the case of the normal direction, the friction coefficients had the order of configurations I, II, and III. The carbon fiber and matrix material showed a surface with discontinuity. Preferentially, a crack occurred on the side where these were in contact, and a delamination phenomenon was generated. In the case of the direction normal to the relative friction surface, debonding occurred between the carbon fiber and the resin at the friction surfaces, and this was directly affected by the fiber ply orientation. However, in this case, the debonding was unable to increase before the length of the carbon fiber was reduced by wear. In the case of the direction parallel to the relative friction surface, the debonding was considered to be a result of the increase in the friction coefficient because the contact area of the relative friction surface and carbon fiber was relatively wide.

\subsection{Results of Fracture Surface Analysis}

Friction tests were carried out to observe the destroyed morphology in the interface between the resin and fiber, and the friction surface of the specimen was analyzed using an electron microscope.The friction shape for each specimen was shown in Fig. 3. First, in the case of the direction normal to the relative friction surface, extreme breaks in the carbon fiber occurred in the specimens with configuration II and III. In addition, in case of the direction parallel to the relative friction surface, the extreme breaks in the carbon fiber occurred in the specimens with configuration I. This appears to be a phenomenon where the bending stress acts on the carbon fiber. On the other hand, in the specimens with configurations I and II, the tensile stress and bending stress acted on the carbon fiber. Thus, the grinding fiber and breaking fiber could be confirmed. 


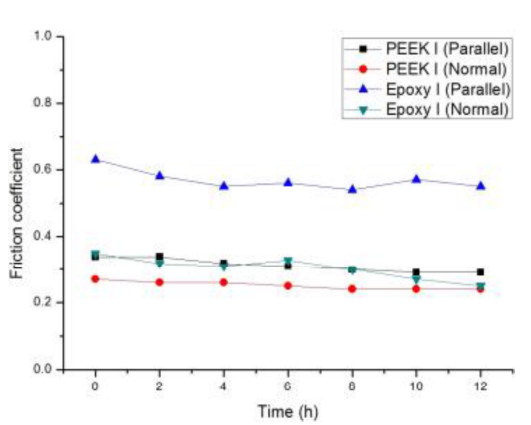

(a) Configuration I

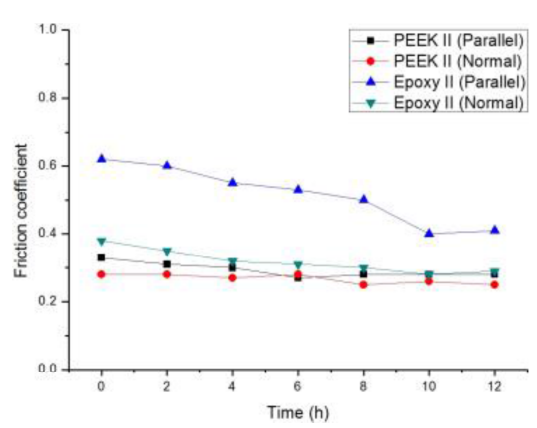

(b) Configuration II

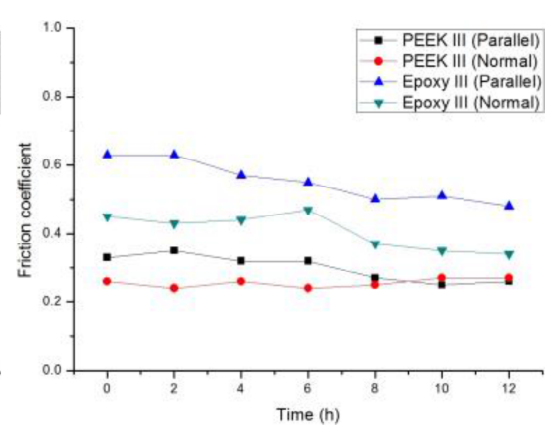

(c) Configuration III

Fig. 2. Effect of Ply Configuration on Friction Coefficient

\subsection{Results of Fracture Surface Analysis}

Friction tests were carried out to observe the destroyed morphology in the interface between the resin and fiber, and the friction surface of the specimen was analyzed using an electron microscope.The friction shape for each specimen was shown in Fig. 3. First, in the case of the direction normal to the relative friction surface, extreme breaks in the carbon fiber occurred in the specimens with configuration II and III. In addition, in case of the direction parallel to the relative friction surface, the extreme breaks in the carbon fiber occurred in the specimens with configuration I. This appears to be a phenomenon where the bending stress acts on the carbon fiber. On the other hand, in the specimens with configurations I and II, the tensile stress and bending stress acted on the carbon fiber. Thus, the grinding fiber and breaking fiber could be confirmed.

\section{Conclusion}

In this study, the composites were manufactured Carbon/PEEK composites and Carbon/Epoxy composites. The mechanical properties according to the friction and wear were also investigated. Also, this study analyzed the effect of the friction on the composites according to the fiber ply orientation. The following results were obtained from these data.

(1) The friction properties of the specimens manufactured with the different matrix materials were tested. It was found that the carbon/PEEK composites showed better properties than the carbon/epoxy composites. It was determined that this resulted because the properties of the PEEK resin itself were better than those of the epoxy resin.

(2) A larger friction coefficient was generally displayed in the case of the direction parallel to the relative friction surface.

(3) There were no clear-differences seen in the friction coefficient according in relation to the carbon fiber ply orientation.

(4) In the SEM results, the tensile stress and bending stress were found to act on the carbon fiber.

Thus, it was confirmed that the carbon/PEEK composites had sufficient mechanical properties to replace the materials used in the existing artificial hip joint.

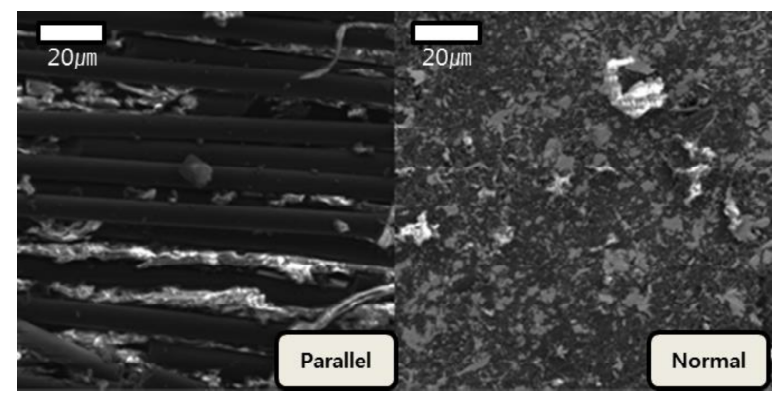

(a) Configuration I for carbon/epoxy

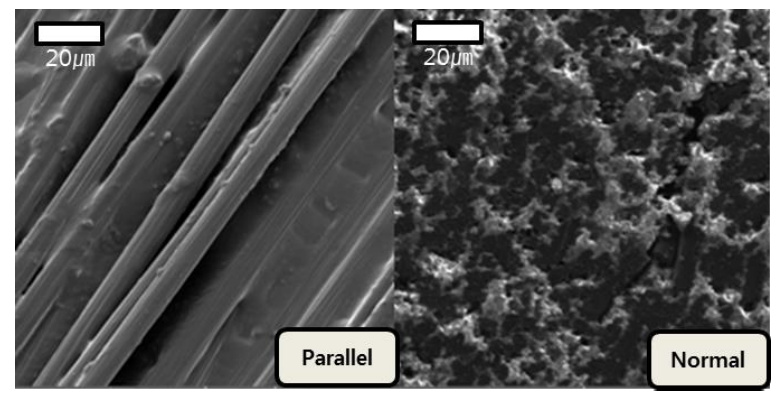

(b) Configuration I for carbon/PEEK 


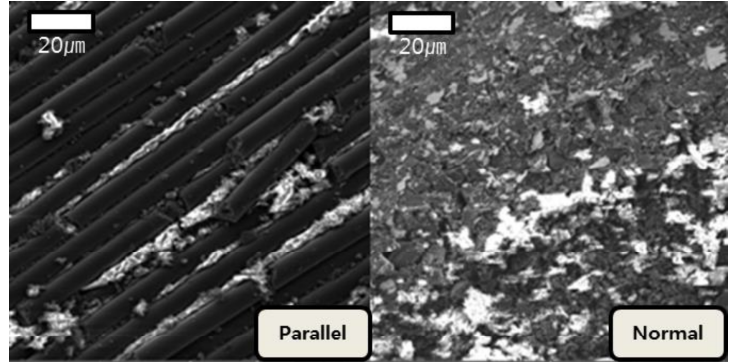

(c) Configuration II for carbon/epoxy

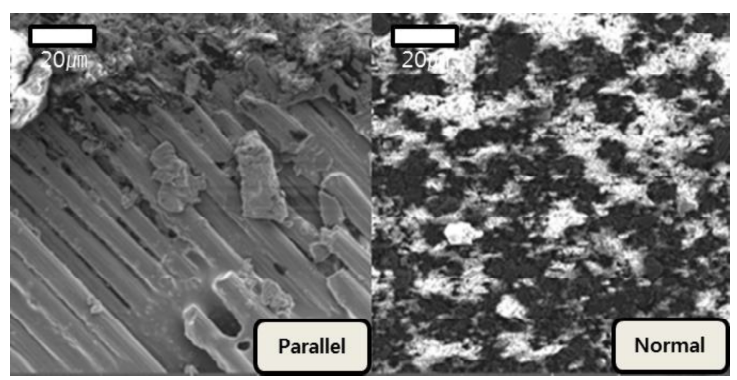

(d) Configuration II for carbon/PEEK

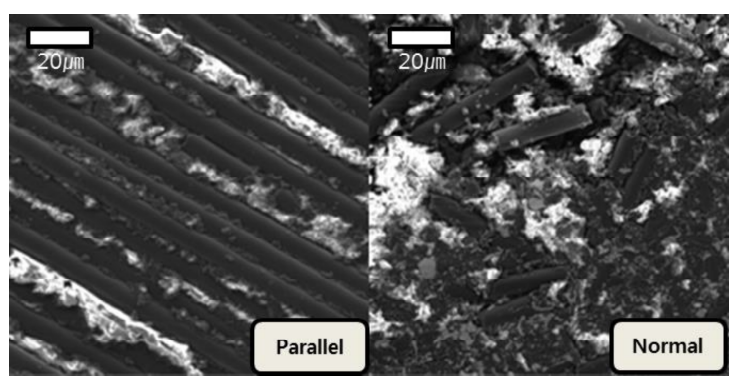

(e) Configuration III for carbon/epoxy

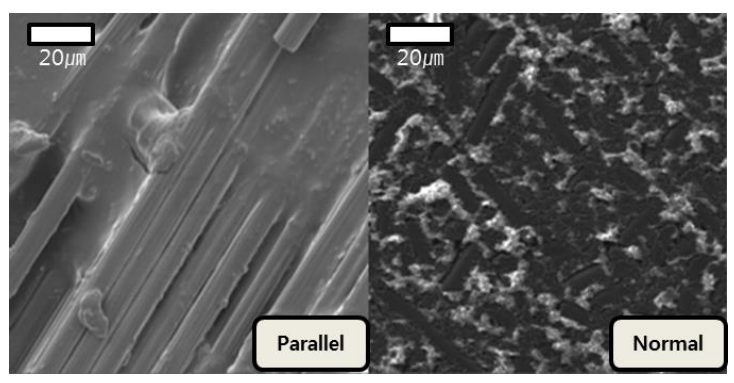

(f) Configuration III for carbon/PEEK

Fig. 3. SEM Observation

\section{Acknowledgements}

This work (Grants No. S2046151) was supported by Korean Small Business Innovation Research Program and Research Institute funded Korea Small and Medium Business Administration in 2012.

\section{References}

[1] Y. H. Kim, S. W. Yoon, and R. Murakami, Design of Artificial Hip Joint by Carbon/PEEK Composites, Advanced Materials Research, 774-776 (2013) 1336-1341.

[2] Y. H. Kim, S. W. Yoon, and R. Murakami, Effect of Moisture Absorption and Fiber Ply Orientation for Artificial Hip Joint on the Mechanical Properties of Carbon/PEEK Composites, Advanced Materials Research, 774-776 (2013) 1326-1335.

[3] Y. H. Kim, S. W. Yoon, and R. Murakami, Mechanical Properties of Carbon/PEEK Composites According to the Fiber Ply Orientation and Sizing Removal of Carbon Fiber for Artificial Hip Joint, Advanced Materials Research, 750-752 (2013) 164-175.

[4] Ikeda M, Komatsu SY, Sowa I, and Niinomi M, Aging behavior of the Ti-29Nb-13Ta-4.6Zr new $b$ alloy for medical implants, Metall Mater Trans A, 33 (2002) 487-493.

[5] Niinomi M, Recent research and development in titanium alloys for biomedical applications and healthcare goods, Sci. Technol. Adv. Mater., 4 (2003) 445-454.

[6] Bania PJ, Lenning GA, and Hall JA, Development and properties of Ti-15V-3Al-3Sn-3Cr. In: Boyer RR, Rosenberg HW, editors. b Titanium Alloys in the 1980's. Warrendale, PA: AIME; (1984) 209-229.

[7] Kamachi Mudali U, Sridhar TM, and Baldev R, Corrosion of bioimplants. Sadhana 28 (2003) 601-637.

[8] S. W. Chun, Y. M. Kim, and H. J. Kang, Tribological properties of laminated fiber orientation in carbon fiber/epoxy composites for reflecting material of the electromagnetic wave, J. Korean Ind. Eng. Chem., 10-5 (1999) 778-783.

[9] S. K. Ryoo and K. W. Kim, A study on friction and wear behavior of carbon fiber reinforced polyetheretherketone, The Korean Society of Mechanical Engineers, 25-6 (2001) 930-937. 